\title{
El Diccionario Monolingüe Pedagógico y la Enseñanza de Vocabulario: reflexiones teóricas y propuesta de actividad
}

\author{
Renato Rodrigues Pereira ${ }^{1}$
}

\begin{abstract}
Resumen: El objetivo de este artículo es reflexionar sobre la importancia y sobre el uso de los diccionarios monolingües pedagógicos como materiales didácticos que mucho pueden contribuir para el proceso de enseñanza y de aprendizaje de Español como Lengua Extranjera (E/LE). Para ello, además de los aportes teóricos y metodológicos de la Lexicografía Pedagógica (LEXPED), buscamos apoyo en autores que valoran el desarrollo del conocimiento léxico en el estudio de lenguas y proponemos una actividad con ejercicios dirigidos cuyo objetivo es demostrar que léxico, texto y diccionario caminan juntos, como posibilitadores de significados e informaciones para la realización de los sentidos que deseamos.
\end{abstract}

Palabras clave: Diccionario; Léxico; Enseñanza.

The Pedagogical Monolingual Dictionary and the Teaching of Vocabulary: theoretical reflections and proposal of activities

Abstract: The purpose of this article is to reflect on the importance and the use of pedagogical monolingual dictionaries as didactic materials that can contribute a lot in the process of teaching and learning Spanish as a Foreign Language (ELE). For this, in addition to the theoretical and methodological contributions of the Pedagogical Lexicography, we seek support in authors who value the development of lexical knowledge in the study of language and propose an activity with directed exercises, whose objective is to demonstrate that lexicon, text and dictionary walk together as facilitators of meanings and information for the realization of the senses we desire.

KEYWODS: Dictionary; Lexicon; Teaching.

O Dicionário Monolíngue Pedagógico e o Ensino de Vocabulário: reflexões teóricas e proposta de atividade

Resumo: O objetivo deste artigo é refletir sobre a importância e o uso dos dicionários monolíngues pedagógicos enquanto materiais didáticos que muito podem contribuir no processo de ensino e de aprendizagem de Espanhol como Língua Estrangeira (L/LE). Para isso, além dos aportes teóricos e metodológicos da Lexicografia Pedagógica (LEXPED), buscamos apoio em autores que valorizam o desenvolvimento do conhecimento léxico no estudo de línguas e propomos uma atividade com exercícios dirigidos cujo objetivo é demonstrar que léxico, texto e dicionário caminham juntos, como possibilitadores de significados e informações para a realização dos sentidos que desejamos.

Palavras-chave: Dicionário; Léxico; Ensino.

\footnotetext{
${ }^{1}$ Universidade Federal de Mato Grosso do Sul (UFMS), Três Lagoas - MS - Brasil. Docente e coordenador do Programa de Pós-Graduação em Letras (PPGLetras). ORCID <https://orcid.org/0000-0001-9870-3780>. E-mail: astrolabiorrp30@gmail.com
} 


\section{Introducción}

En el proceso de enseñanza y de aprendizaje de una lengua extranjera, tener acceso a buenos materiales didácticos ${ }^{2}$ suele ser muy importante para que las distintas actividades de comunicación sean realizadas de forma más efectiva. Los diccionarios pedagógicos, en este contexto, pueden cumplir un papel sustancial en la didáctica de lenguas, pues las informaciones disponibles, en cada parte de sus organizaciones estructurales, generalmente son registradas con la intención de facilitar la búsqueda del potencial consultante y, por consiguiente, el aprendizaje de la información deseada.

En este artículo, presentamos algunas consideraciones respecto a la importancia y al uso del diccionario monolingüe pedagógico (impreso y electrónico) destinado a estudiantes en proceso de aprendizaje de una lengua, más específicamente en situaciones de aprendizaje de E/LE, y presentamos también una actividad dirigida ${ }^{3}$ que ha sido pensada para un aprendiz específico: el estudiante brasileño que se encuentra en los niveles intermedios y avanzados de aprendizaje $^{4}$ de la lengua.

Para la actividad, elaboramos ejercicios con foco en las unidades léxicas homónimas del español, puesto que los valores semánticos y por veces distintas grafías suelen causar dudas al estudiante no nativo de la lengua española. Elaboramos dicha actividad a fin de posibilitar al alumno el entendimiento del diccionario monolingüe como una importante herramienta de consulta cuando esté haciendo actividades de lectura, de expresión oral o de escritura.

Para cumplir nuestros objetivos, nos orientamos por los principios teóricos y metodológicos de la LEXPED $^{5}$ y por las contribuciones de un campo que mucho ha evolucionado en las últimas décadas: la Enseñanza del Vocabulario (En adelante EV).

\footnotetext{
${ }^{2}$ Se comprende por materiales didácticos los distintos recursos impresos, audiovisuales, multimedia etc, que se emplean en el proceso de enseñanza y de aprendizaje de una lengua. Para una mejor comprensión sobre qué son y los distintos tipos existentes, véase Eres Fernández (2010, p. 73) y el Diccionario de Términos Clave de E/LE, disponible en: https://cvc.cervantes.es/ensenanza/biblioteca_ele/diccio_ele/default.htm. Acceso el: 29 de septiembre de 2018.

3 Por actividad dirigida, nos referimos a ejercicios cuyas orientaciones llevan el estudiante a seguir, secuencialmente, instrucciones de cómo hacer cada tarea, de forma que cada etapa completa la anterior en términos de aprendizaje de los contenidos en cuestión y, aún, induce al uso de diccionario.

${ }^{4}$ Respecto a los niveles de aprendizaje de un estudiante, sugerimos la lectura del MCER (2002), en su capítulo 3.

${ }^{5}$ El término Lexicografía Pedagógica por veces es sustituido por Lexicografía Didáctica o viceversa. Hernández (1998) utiliza este último, pero resalta que hay quien prefiera Lexicografía Pedagógica. En la Lexicografía
} 


\section{Lexicografía Pedagógica y enseñanza del vocabulario: interfaces}

La LEXPED es un área de la Lexicografía General responsable por los estudios relacionados a los diccionarios pedagógicos destinados a los aprendices de lengua materna o extranjera. Por tanto, nos posibilita reflexiones tanto respecto a la elaboración de diccionarios, como también al uso de esos diccionarios en las clases. En este escenario, se percibe que si los diccionarios son pensados y elaborados en el ámbito de los estudios teóricos y prácticos de la LEXPED, tanto los estudiantes como los profesores pueden disfrutar de esos instrumentos pedagógicos que mucho contribuyen a la enseñanza de una lengua.

Welker (2008) divide la LEXPED en dos campos: i) LEXPED teórica - responsable por todo el tipo de estudio que se relaciona a diccionarios pedagógicos; y ii) LEXPED práctica - que se ocupa de la producción de esos diccionarios. Para el autor, esas obras se diferencian de los diccionarios comunes por la preocupación con el aprendiente de lenguas, considerando sus necesidades y habilidades.

Krieger (2011, p. 106), por su parte, establece dos principios esenciales en el ámbito de la LEXPED, a saber: i) la busca de la adecuación del diccionario; ii) el uso productivo para los distintos proyectos de enseñanza y aprendizaje de lenguas. La autora nos plantea aún que a los dos ítems deben ser agregados

la comprensión de que el diccionario es un texto, con reglas propias de organización, que sistematiza inúmeras informaciones de carácter lingüístico, cultural y pragmático. De ello resulta su exponente papel pedagógico, bien como el principio de que así como hay libros didácticos adecuados a los diferentes niveles de enseñanza, de igual modo, se debe proceder a la escoja del diccionario adecuado a las necesidades de aprendizaje de los alumnos (KRIEGER, 2011, p. 106, traducción nuestra) ${ }^{6}$.

Reflexionemos que, para que el uso productivo mencionado por la autora ocurra a contento, es necesario que el profesor, el alumno y los materiales didácticos estén en sincronía. O sea, es pertinente que todas las personas involucradas en el proceso de enseñanza y de aprendizaje sean conocedoras de las distintas y complementarias tipologías de

hispánica, por ejemplo, el predicativo didáctico/a parece ganar más espacio respecto al pedagógico/a, distinto, pues, de Brasil. A ese respecto, sugerimos consultar Hernández (1998), Welker (2008).

6 a compreensão de que o dicionário é um texto, com regras próprias de organização, que sistematiza inúmeras informações de caráter linguístico, cultural e pragmático. Daí resulta seu exponencial papel pedagógico, bem como o princípio de que assim como há livros didáticos adequados aos diferentes níveis de ensino, de igual modo, deve-se proceder à escolha do dicionário adequado às necessidades de aprendizagem dos alunos (KRIEGER, 2011, p. 106). 
diccionarios, así como de las varias informaciones lingüísticas y extralingüísticas que tales repertorios nos ofrecen.

En este contexto, destacamos la necesidad, por parte del profesor a priori, y enseguida del estudiante, de conocer una obra lexicográfica en todas sus posibilidades de información. A ese respecto, mencionamos a Krieger (2007) y a Nadin (2013), quienes destacan que el potencial didáctico del diccionario no siempre suele ser explotado en todas sus posibilidades en clase, puesto que en la mayoría de los contextos de enseñanza, los profesores aún desconocen las características estructurales y las importantes funciones de las obras lexicográficas.

Así, se entiende que si investigaciones relacionadas a la formación de profesores en el ámbito de la LEXPED, así como propuestas de materiales didácticos que contengan actividades dirigidas que induzcan al alumno a utilizar el diccionario, ocurren de forma satisfactoria, posiblemente habrá una evolución respecto al uso productivo de las distintas obras lexicográficas existentes en las clases de lenguas y, consecuentemente, habrá también la continuidad de proyectos lexicográficos de naturaleza pedagógica.

En el entorno de la EV, la atención pedagógica se vuelve, especialmente al aprendizaje de las funciones y significados de las unidades léxicas ${ }^{7}$, puesto que el léxico de una lengua es lo que más representa los anhelos, intenciones designativas de naturaleza general, aspectos sociales, lingüísticos e históricos de un pueblo.

Debido al carácter emblemático que el léxico posee, desde niños, cuando comenzamos a pronunciar los primeros sonidos de palabras "del léxico, echamos mano en cuanto empezamos a hablar, leer o escribir, pues el léxico constituye uno de los pilares fundamentales de la comunicación verbal [...] (ALVAR EZQUERRA, 2003, p. 7 - destaque nuestro).

Por eso, la EV se vuelve aún más importante en la enseñanza y en el aprendizaje de lenguas, a medida que las personas involucradas en el proceso empiezan a valorar las lexías como poseedoras de significados y funciones, y que, por ello, resultan posibilitadoras de sentidos en los diferentes contextos discursivos.

Morante Vallejo (2005, p. 8), al discutir sobre el desarrollo del conocimiento léxico en segundas lenguas, nos presenta que "tanto los aprendices como los hablantes nativos perciben

\footnotetext{
${ }^{7}$ El término unidades léxicas, en el ámbito de las Ciencias del Léxico, se refiere a uno, dos o más significantes que juntos poseen una unidad de sentido. A ese respecto, sugerimos conferir Morante Vallejo (2005) y Biderman (2005).
} 
los errores léxicos como obstáculos para la comunicación. Ampliar el vocabulario es una necesidad incluso para los aprendices avanzados".

Higueras (2000, p. 13), en este escenario, destaca que los alumnos siempre manifiestan que a veces

no pueden expresar lo que desean porque desconocen el léxico adecuado. [...] aunque parafrasear es una estrategia legítima que deben saber emplear los alumnos, a veces sus producciones se prolongan innecesariamente, e incluso se producen errores de comprensión, por el desconocimiento del léxico.

Nuestra experiencia como profesor de lenguas, en especial de portugués como lengua materna y de español como lengua extranjera, nos posibilita comulgar la asertiva de los autores citados, puesto que en muchas situaciones de enseñanza, nuestros alumnos no consiguen expresar lo que desean por falta de conocimiento de los distintos aspectos del léxico de la lengua en estudio.

En ese contexto, resaltamos todavía las palabras de Antunes (2007) para quién el léxico es más que un listado de palabras a disposición de los hablantes. "Es un depositario de recortes con que cada comunidad ve el mundo, las cosas que lo circundan o el sentido de todo (ANTUNES, 2007, p. 42, traducción nuestra). Para la estudiosa, es en los textos que elaboramos que el léxico recubre distintas funciones y que, como unidades de sentido, las palabras constituyen las piezas con que se teje la red de significados del texto, puesto que son ellas que van materializando y mediando las intenciones de nuestro decir.

Observemos, por lo expuesto, que el léxico es objeto de estudio y descripción tanto de la LEXPED como de la EV, pero con funciones distintas. En aquella, se estudia y se describe el léxico desde una perspectiva pedagógica a fin de registrarlo en repertorios lexicográficos destinados a aprendices de lenguas para que los estudiantes tengan materiales organizados de forma más didáctica y para que sirvan de apoyo en las actividades de aprendizaje de lenguas. En esta última, importa valorar el aprendizaje del léxico en sus múltiples sentidos y funciones, de forma que el alumno consiga establecer diálogos escritos y hablados de manera competente y de acuerdo con el contexto en que se encuentre.

Por fin, ponemos de relieve la afirmación de Garcia (1977, p. 143), quien resalta que si disponemos de palabras suficientes y adecuadas a la expresión del pensamiento de manera clara, fiel y precisa, estamos en mejores condiciones de asimilar conceptos, de reflexionar, de escoger, de juzgar, en relación a otros cuyo léxico sea insuficiente o impreciso para la tarea de la comunicación. 
Los diccionarios como materiales didácticos, en especial, ocupan un importante papel en la enseñanza de lenguas, sobre todo si los utilizamos en todas sus posibilidades y tipologías. Entre los que hay en el mundo académico, como los bilingües, los monolingües, los semibilingües, los especiales de lengua (de antónimos, de sinónimos, de homónimos ...) etc, nos detendremos, a continuación, en las características, funciones e importancia de los diccionarios monolingües, específicamente de los destinados a aprendices de $\mathrm{E} / \mathrm{LE}^{8}$.

\section{El diccionario monolingüe de aprendizaje: características, funciones e importancia}

En términos generales, los diccionarios monolingües de aprendizaje (DMA) pueden ofrecer informaciones gramaticales, sociolingüísticas, definiciones, ejemplos de uso e informaciones enciclopédicas, por ejemplo, que mucho pueden contribuir para el proceso de aprendizaje de una lengua, ya que tales informaciones le posibilitan al estudiante mantener contacto con discursos oriundos de distintos contextos y, por consiguiente, elaborar sus propios enunciados.

De acuerdo con Hernández (1996), los DMA dirigidos a estudiantes extranjeros deben ser distintos de los diccionarios monolingües para nativos, pues también las necesidades son distintas. Para el autor, los estudiantes nativos usan el diccionario mayoritariamente para comprobar la ortografía y para la comprensión. Ya los estudiantes extranjeros, a su vez, necesitan del diccionario tanto para la comprensión como para la producción.

Martín García (1999, p. 17), por su parte, resalta que los diccionarios de esa tipología

[...] deben incluir ejemplos que permitan determinar el uso de la palabra y aclarar su significado. Asimismo, las definiciones deben ser más claras que en los monolingües para nativos, incluso deben contener información elementar, que puede resultar superflua en muchos casos para un hablante nativo.

Se percibe que los DMA necesitan, por tanto, una mirada más didáctica por parte de los lexicógrafos en la elaboración de esos repertorios, visto que ellos pueden cumplir diferentes funciones en el contexto del proceso de enseñanza y de aprendizaje de una lengua extranjera.

\footnotetext{
${ }^{8}$ A título de ejemplo de diccionarios monolingües para aprendices de E/LE utilizados en Brasil, citemos el Diccionario de español para extranjeros - con el español que se habla hoy en España y en América Latina, de González (2005), el Diccionario Salamanca - español para extranjeros, de Gutiérrez Cuadrado y Pascual Rodríguez (2006) y el Diccionario básico de la lengua española, de Sánchez (2003).
} 
En ese contexto, Hernández (2000), así como Martín García (1999), resalta la pertinencia de ofrecerles, a los alumnos,

diccionarios cuyas definiciones sean auténticas explicaciones, y esto sólo es posible con un diccionario monolingüe pedagógico, que habrá de ser, por muchas razones, distinto de los que se destinan a los hablantes nativos: serían éstos los diccionarios monolingües para usuarios extranjeros (denominados learners's dictionaries en la lexicografía anglosajona; en nuestro ámbito, ha empezado a utilizarse la denominación diccionarios de aprendizaje) (HERNÁNDEZ, 2000, p. 94).

Como es posible observar, los DMA pueden cumplir importantes funciones debido a las características que poseen. En ese entorno, merece la pena acordarnos de que en el contexto de la enseñanza de lenguas extranjeras, dependiendo del nivel de conocimiento de los estudiantes, como aquellos que están en nivel básico de aprendizaje, por ejemplo, es pertinente que se elija, por parte de los alumnos y de los profesores, diccionarios que atiendan a las necesidades de los alumnos, de acuerdo con sus competencias comunicativas ${ }^{9}$, en el período de aprendizaje en que se encuentran. Por ello, se hace necesario que discurramos todavía sobre los diccionarios bilingües, pues en algunas situaciones de producción o recepción de texto él también es indispensable, como vamos a demostrar más adelante.

No obstante, vale destacar que escoger un repertorio lexicográfico que pueda ofrecer "todo" lo que un potencial usuario necesita es casi imposible. Primero, porque lo que precisa uno no necesariamente necesita el otro, puesto que distintos son los aspectos lingüísticos y extralingüísticos conocidos o no por parte del alumno. Y eso determina su grado de conocimiento sobre la lengua, sobre su uso. Segundo, porque el diccionario, tanto en el soporte libro impreso o en el soporte electrónico, nunca va a conseguir abarcar todo el acervo lexical de una lengua, así como los aspectos morfo-funcionales y pragmáticos de un idioma.

Lo que podemos afirmar es que en toda actividad de comunicación, el usuario de una lengua está siempre basado en habilidades de recepción y de producción, sean orales o escritas. Y que en este entorno el diccionario, tanto el bilingüe cuanto el monolingüe, puede

\footnotetext{
9 Almeida Filho (2013), tras las contribuciones teóricas de Chomsky (1965), Hymes (1979), Canale y Swain (1980), Tarone (1980) y Widdowson (1989), entre otros, plantea la competencia comunicativa como el resultado de competencias que el participante de la interacción comunicativa, dependiendo del grado de acceso a los conocimientos disponibles tiene o adquiere, como: competencia lingüística que demanda conocimientos sobre el código en cuestión; competencia sociocultural, en que los conocimientos extralingüísticos y estéticos son evidenciados en situaciones de interacción; competencia meta, cuando los conocimientos metalingüísticos y metacomunicativos son resaltados, como forma de posibilitar una reflexión sobre sus valores funcionales y pragmáticos; competencia estratégica, referente a conocimientos y mecanismos de sobrevivencia en la interacción, es decir, la capacidad de producir y comprender textos adecuados a la producción de efectos de sentidos deseados en situaciones específicas y concretas de interacción comunicativa.
} 
ser utilizado en actividades de codificación o producción (expresión oral o escrita) y descodificación o comprensión (lectura y comprensión oral). Martínez Marín (1990), a ese respecto, ya destacaba que

Una de las novedades fundamentales que ha aportado la lexicografía aplicada a los "diccionarios para la enseñanza-aprendizaje" de lenguas extranjeras es el atender al aspecto de la producción, es decir, la codificación (enunciados y textos de diversos tipos, según el nivel de los diccionarios, que depende de la clase de destinatarios de la obra) y no solamente al de la comprensión, esto es la descodificación. De esta forma el diccionario es pensado - e incluso diseñado - para ser útil al conocimiento activo de la lengua tanto como al pasivo. Y este hecho tiene consecuencias importantes en la información de los artículos del diccionario, especialmente en lo relativo a algunos aspectos de la misma y en particular en la información gramatical y en las llamadas observaciones sobre el uso de los vocablos (indicaciones sobre estímulos, sobre valores pragmáticos, etc.) (MARTÍNEZ MARÍN, 1990, p. 310).

Para el autor, el diccionario monolingüe de carácter didáctico cumple su función como material de apoyo en tareas no solo de descodificación, como también en actividades de codificación.

Hernández (1998), por su parte, sobre las funciones de los diccionarios monolingües y bilingües, expone el monolingüe solo como de función descodificadora.

[...] los diccionarios monolingües cumplen con una función meramente descodificadora de mensajes elaborados en la propia lengua del usuario, y los bilingües, además de la función descodificadora (traducir textos de una lengua desconocida a la materna) una función codificadora (elaboración de mensajes en una segunda lengua a partir de la primera. A los diccionarios monolingües, pues, sólo se les exige el cumplimiento de una función descodificadora y a los bilingües la capacidad de descodificar y codificar textos en una segunda lengua de la que se poseen, al menos, unos conocimientos elementares (HERNÁNDEZ, 1998, p. 70).

Sánchez López (2013, p. 23), a su vez, resalta la función codificadora del diccionario monolingüe en procesos de traducción, cuando ocurre la elaboración de mensajes en una segunda lengua a partir de la primera. La investigadora enfatiza aún que ésta es una función que generalmente es atribuida al monolingüe, como esclarece Hernández (1998), y no al bilingüe.

Para Sánchez López (2013, p. 24), la función codificadora "es una cualidad que se le reconoce a los diccionarios didácticos” en general. Así como Martínez Marín (1990) y Sánchez López (2013), también aludimos al DMA como siendo también de función 
codificadora y no solo descodificadora. La actividad que presentamos más delante en este texto demuestra esa función.

Frente a las observaciones en los párrafos anteriores en relación a las características de los DMA, en especial, e igualmente a las funciones de los monolingües y los bilingües, ponemos énfasis, en la secuencia, a la importancia de los diccionarios monolingües, sobre todo cuando los alumnos están en niveles intermedios y avanzados de aprendizaje de una lengua extranjera. Pero antes nos parece conveniente presentar qué nos plantea el MCER (2002) respecto a las competencias de los alumnos de niveles básicos, intermedios y avanzados - A1 y A2 (básicos), B1, B2 (intermedios) y C1 y C2 (avanzados), como forma de justificar nuestro énfasis. El Cuadro 1 nos da una idea de las habilidades de esos alumnos.

Cuadro 1: Niveles comunes de referencia: escala global

\begin{tabular}{|c|c|c|}
\hline \multirow{2}{*}{ 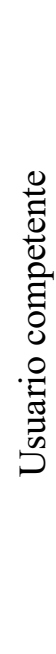 } & & $\begin{array}{l}\text { capaz de comprender con facilidad prácticamente todo lo que oye o lee. } \\
\text { be reconstruir la información y los argumentos procedentes de diversas fuentes, ya sean } \\
\text { lengua hablada o escrita, y presentarlos de manera coherente y resumida. } \\
\text { lede expresarse espontáneamente, con gran fluidez y con un grado de precisión que le } \\
\text { rmite diferenciar pequeños matices de significado incluso en situaciones de mayor } \\
\text { mplejidad. }\end{array}$ \\
\hline & $\mathrm{C} 1$ & $\begin{array}{l}\text { capaz de comprender una amplia variedad de textos extensos y con cierto nivel de } \\
\text { igencia, así como reconocer en ellos sentidos implícitos. } \\
\text { be expresarse de forma fluida y espontánea sin muestras muy evidentes de esfuerzo } \\
\text { ra encontrar la expresión adecuada. } \\
\text { lede hacer un uso flexible y efectivo del idioma para fines sociales, académicos y } \\
\text { ofesionales. } \\
\text { lede producir textos claros, bien estructurados y detallados sobre temas de cierta } \\
\text { mplejidad, mostrando un uso correcto de los mecanismos de organización, articulación } \\
\text { cohesión del texto. }\end{array}$ \\
\hline \multirow{2}{*}{ 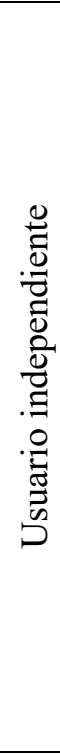 } & & $\begin{array}{l}\text { capaz de entender las ideas principales de textos complejos que traten de temas tanto } \\
\text { acretos como abstractos, incluso si son de carácter técnico, siempre que estén dentro de } \\
\text { campo de especialización. } \\
\text { ede relacionarse con hablantes nativos con un grado suficiente de fluidez y naturalidad, } \\
\text { modo que la comunicación se realice sin esfuerzo por parte de los interlocutores. } \\
\text { ede producir textos claros y detallados sobre temas diversos, así como defender un } \\
\text { to de vista sobre temas generales, indicando los pros y los contras de las distintas } \\
\text { iones. }\end{array}$ \\
\hline & B1 & $\begin{array}{l}\text { capaz de comprender los puntos principales de textos claros y en lengua estándar si } \\
\text { an sobre cuestiones que le son conocidas, ya sea en situaciones de trabajo, de estudio o } \\
\text { ocio. } \\
\text { e desenvolverse en la mayor parte de las situaciones que pueden surgir durante un } \\
\text { e por zonas donde se utiliza la lengua. } \\
\text { capaz de producir textos sencillos y coherentes sobre temas que le son familiares o en } \\
\text { que tiene un interés personal. } \\
\text { de describir experiencias, acontecimientos, deseos y aspiraciones, así como justificar } \\
\text { vemente sus opiniones o explicar sus planes. }\end{array}$ \\
\hline$\widetilde{g}$ & A & capaz de comprender frases y expresiones de uso frecuente re \\
\hline
\end{tabular}




\begin{tabular}{|c|c|}
\hline & $\begin{array}{l}\text { Sabe comunicarse a la hora de llevar a cabo tareas simples y cotidianas que no requieran } \\
\text { más que intercambios sencillos y directos de información sobre cuestiones que le son } \\
\text { conocidas o habituales. } \\
\text { Sabe describir en términos sencillos aspectos de su pasado y su entorno, así como } \\
\text { cuestiones relacionadas con sus necesidades inmediatas. }\end{array}$ \\
\hline A1 & $\begin{array}{l}\text { Es capaz de comprender y utilizar expresiones cotidianas de uso muy frecuente, así como, } \\
\text { frases sencillas destinadas a satisfacer necesidades de tipo inmediato. } \\
\text { Puede presentarse a sí mismo y a otros, pedir y dar información personal básica sobre su } \\
\text { domicilio, sus pertenencias y las personas que conoce. } \\
\text { Puede relacionarse de forma elemental siempre que su interlocutor hable despacio y con } \\
\text { claridad y esté dispuesto a cooperar. }\end{array}$ \\
\hline
\end{tabular}

Fuente: MCER (2002, p. 26).

Por lo expuesto, se entiende que el estudiante que se encuentra en niveles básicos de aprendizaje (A1 y A2), por ejemplo, por el poco conocimiento sobre la lengua que aún posee, se recomienda la utilización de un diccionario bilingüe. Así, en el proceso de descodificación, el alumno debe comprender un mensaje en una lengua que no es su lengua materna en situaciones de lectura y, además, por el proceso de codificación, puede el diccionario bilingüe posibilitar la elaboración de mensajes, aunque menos elaboradas, en una segunda lengua o extranjera, a partir de la primera.

Ya en los niveles intermedio y avanzado (B1, B2 y C1, C2) - además del diccionario bilingüe, en casos específicos que el estudiante no conozca una palabra que supla su necesidad de producción en la lengua extranjera, por ejemplo - el diccionario monolingüe suele ser muy importante y útil. El estudiante de E/LE, ya poseedor de habilidades y competencias múltiples que le permiten no solo leer y comprender un texto con más fluidez, como también producir enunciados con mayor destreza, tendrá en el diccionario monolingüe pedagógico informaciones diversas, como las ya explicitadas anteriormente, que le otorga la función codificadora y descodificadora de mensajes.

Castillo Carballo y García Platero (2003, p. 344) al explicar sobre cuándo usar el diccionario bilingüe y el monolingüe, esclarecen que "es innegable que en los primeros años de aprendizaje los repertorios bilingües son un instrumento eficaz. Ciertamente, el usuario encontrará con facilidad las equivalencias necesarias, dado que su conocimiento de la lengua meta no es elevado...". Ya refiriéndose al diccionario monolingüe, los autores dicen que, por el contrario, esa situación se cambia, pues "a medida que va adquiriendo en su proceso de aprendizaje un mayor conocimiento cultural y lingüístico de la nueva realidad a la que se está enfrentando, sus necesidades van a aumentar considerablemente".

Además de lo expuesto, destacamos las palabras de Prado Aragonés (2004, p. 157158), quien nos esclarece que los diccionarios “(...) no son sólo obras lingüísticas (...), sino 
que también son instrumentos culturales que incluyen información sobre el mundo y la cultura de la comunidad que habla esa lengua". La autora señala también que las informaciones culturales y enciclopédicas se presentan en el diccionario, en algunas ocasiones en la definición, pero fundamentalmente, a través de los ejemplos, en los que se muestran contextualizados los modelos de uso de la lengua y también en las marcas pragmáticas de uso, con la fraseología e ilustraciones, lo que, una vez más, cualifica el DMA como un diccionario también de función codificadora, de forma que las informaciones disponibles en esa tipología de diccionarios contribuyen en el desarrollo de la competencia comunicativa de los alumnos en las varias prácticas de enseñanza, permitiéndoles realizar distintas actividades en el aula y fuera de ella $y$, por consiguiente, les posibilita ampliar los conocimientos que ya poseen como estudiantes.

A partir de las reflexiones presentadas hasta ahora en el texto, pasamos a discutir sobre la homonimia en el proceso de enseñanza y de aprendizaje del léxico.

\section{La homonimia en la enseñanza y en el aprendizaje del léxico}

En el pasado, más específicamente hasta los años ochenta, cuando teníamos una enseñanza estrictamente de naturaleza formalista de los estudios estructuralistas, la enseñanza de vocabulario no pasaba de un listado de palabras destinado a tareas de memorización y/o traducción ${ }^{10}$. Las palabras eran tratadas en términos secundarios en relación con la gramática.

De los años ochenta hasta la actualidad, gracias a los estudios lexicales con fines de descripción y enseñanza y del advenimiento de corrientes de estudios, como la Lingüística Textual, el Análisis del Discurso, la Lingüística Aplicada, la Sociolingüística y la Pragmática, por ejemplo, la enseñanza en general ha dado un salto en evolución.

En ese contexto, el léxico pasa a ser visto como posibilitador de sentidos. La enseñanza del léxico, en una perspectiva funcional y pragmática, se vuelve necesaria, a medida que los estudiantes son puestos en situaciones en que necesitan producir o comprender discursos auténticos y de acuerdo con la intención comunicativa en cuestión. Aquí, nos referimos a los principios provenientes del enfoque comunicativo.

La homonimia, en términos generales, es un fenómeno lingüístico que se establece cuando dos o más palabras se distancian completamente en términos de sus significados y poseen semejanzas o son iguales en relación a su forma gráfica. Es decir, si una palabra posee

\footnotetext{
${ }^{10}$ Para que se tenga una visión más alargada sobre cómo era vista la enseñanza del léxico desde las escuelas estructuralistas hasta las contemporáneas, sugerimos la lectura de Morante Vallejo (2005).
} 
una misma forma gráfica y fónica, pero significados completamente distintos, estamos ante un homónimo ${ }^{11}$ homógrafo homófono (ej. banco verbo/ banco sustantivo; vino sustantivo/ vino verbo etc); ya si tenemos dos o más palabras con la misma pronunciación, pero con la grafía distinta, nos deparamos con casos de homónimos homófonos no homógrafos (ej. tubo sustantivo/tuvo verbo.; baca sustantivo/vaca sustantivo etc).

Las formas homónimas en el ámbito de la enseñanza de E/LE no siempre suelen tener la atención que merecen en los libros de textos disponibles en las escuelas, por lo menos es lo que hemos observado en cuanto profesor de lengua y supervisor de prácticas obligatorias en el grado de Portugués/Español en una universidad pública.

En este contexto, destacamos las palabras de Alvar Ezquerra (2003, p. 35-36), para quien no cabe duda que "habrá que avisar a nuestros estudiantes, ya desde el inicio del aprendizaje de la lengua, de los problemas que pueden presentarse con los homófonos". Los estudiantes de E/LE, cuando se deparan con situaciones de producción o recepción en que formas homónimas son puestas en comunicación, a veces no consiguen comprender el discurso de forma adecuada al contexto. Por ello, se evidencia la necesidad de estudiar las unidades léxicas homónimas también con la misma atención de las otras palabras de la lengua, para que dudas de naturaleza semántica, ortográfica y de uso puedan ser dirimidas de manera satisfactoria.

Resaltamos que lo que distingue esa parcela del léxico, en términos de importancia o atención en la enseñanza y en el aprendizaje de E/LE, es justamente sus valores semánticos en relación a las otras unidades léxicas de la lengua, así como sus formas ortográficas y pronunciaciones semejantes. Pereira (2018), al reflexionar sobre el tratamiento de formas homónimas en diccionarios, resalta que

el estudiante de lenguas, en especial el de lengua extranjera, cuando está delante de una Unidad Léxica Homónima - ULH, dependiendo del grado de conocimiento de la lengua, [...] puede tener dificultades en saber cuál significado está más de acuerdo con el contexto expreso en la actividad en curso, o si la grafía está adecuada a la representación de determinado significante homónimo (PEREIRA, 2018, p. 20, traducción nuestra) ${ }^{12}$.

\footnotetext{
${ }^{11}$ Sobre el fenómeno de la homonimia, sugerimos la lectura de Ullmann (1964), Biderman (1991), Zavaglia (2003; 2011) y Pereira (2018), quienes nos presentan importantes contribuciones respecto a ese hecho lingüístico.

$12 \mathrm{O}$ estudante de línguas, em especial o de língua estrangeira, ao deparar-se com uma Unidade Léxica Homônima - ULH, dependendo do grau de conhecimento da língua, [...] pode ter dificuldades em saber qual significado está mais de acordo com o contexto expresso na atividade em andamento, ou se a grafia está adequada à representação de determinado significante homonímico (PEREIRA, 2018, p. 20).
} 
Por ello, tener atención a las unidades léxicas homónimas suele ser muy pertinente en contextos de enseñanza y de aprendizaje. En primer lugar, porque forman parte del léxico de la lengua en cuestión y como tal, significan y posibilitan que creamos nuestros significados discursivos, de acuerdo con nuestras intenciones comunicativas. En segundo lugar, porque esas lexías, como ya mencionado anteriormente, reflejan un proceso de alejamiento de significados para una misma forma gráfica y fónica, para los casos de homógrafos homófonos; o distinta forma gráfica, pero con la misma pronunciación, como en los homófonos no homógrafos.

Antes de plantear la actividad dirigida que proponemos en este artículo, destacamos las palabras de Morante Vallejo (2005), como forma de evidenciar la importancia del estudio cualitativo del léxico. Para la autora,

[...] aprender palabras no es un acto acumulativo, basado en la memorización, sino que se trata de un proceso cognitivo complejo, que da lugar al desarrollo de un lexicón mental. El conocimiento comprendido en el lexicón implica tanto conocer las piezas léxicas que lo conforman, como conocer las relaciones que establecen, sus propiedades y las regularidades y arbitrariedades de su uso. Además, desarrollar el lexicón implica desarrollar estrategias de aprendizaje específicas del vocabulario (MORANTE VALLEJO, 2005, p. 26).

Y es con esa intención que proponemos la actividad a continuación, que posibilitará al estudiante adquirir una nueva mirada a las unidades léxicas homónimas del español y, por consiguiente, al léxico general de la lengua.

\section{El diccionario en las clases de E/LE: propuesta de actividad}

Los ejercicios dirigidos que presentamos en la secuencia están organizados con el objetivo de posibilitar el desarrollo del conocimiento léxico del aprendiz de E/LE, más específicamente, del estudiante de la lengua que se encuentra en nivel intermedio o avanzado de aprendizaje, como ya explicamos en la introducción de este artículo.

Los ejercicios se orientan a partir de la lectura, de la comprensión, de la investigación y de la producción de textos escritos y orales. Para tanto, a partir del vocativo ;fíjate!, explicamos, primeramente, qué son las palabras homónimas para, en la secuencia, presentar los ejercicios dirigidos. Objetivamos, con esta actitud didáctica, ofrecer la oportunidad de lectura y reflexión sobre el hecho lingüístico de forma directa, puesto que el estudiante de 
nivel intermedio y avanzado ya consigue realizar comprensiones más dificultosas a algunos estudiantes. Con ello, esperamos que el estudiante comprenda de forma eficaz el fenómeno homonímico y, por consiguiente, desarrolle una mirada más atenta a las otras lexías de la lengua.

\section{Actividad}

\section{¡Fíjate!}

Las palabras homónimas, de forma general, son aquellas cuya grafía y/o pronunciación son iguales o similares, pero difieren en sus significados, de forma que se puede distinguirlos en homófonos no homógrafos: se pronuncian igual pero se escriben de un modo diferente y tienen significados distintos, como en baca/vaca o tubo/tuvo, por ejemplo; y homógrafos homófonos: se difieren también en su significado, pero la grafía es idéntica, así como en vino y banco que cumplen funciones de nombres y también de formas verbales de los verbos tener y bancar respectivamente.

Nota: se puede escribir las respuestas en el cuaderno.

1. Lee el texto abajo y subraya los pares de palabras homónimas que no conozcas.

\section{Un sueño extraño}

Soñé un sueño muy extraño. Soñé que las cosas cobraban vida y sucedían hechos como estos:

Un mimo me hacía un mimo, mientras un perro de caza buscaba una linda casa donde vivir. Una ola de mar me saludaba diciéndome "hola", mientras un sobre cerrado se apoyaba sobre mi regazo con algún mensaje que jamás supe de qué se trataba porque no lo abrí.

Yo quería tomar un té de alguna rica hierba, pero no pude porque la hierba huyó corriendo. Seguro que no quería que la hiervan y por eso escapó.

Me miraba los vellos del brazo, dándome cuenta que nada bellos me parecían y de pronto escucho un ruido muy fuerte. Alguien grita "ay” y yo pregunto: “¿Hay alguien por allí? Me doy cuenta que el tubo de ensayos con el que estaba haciendo experimentos cayó al suelo y me preguntó qué motivos tuvo para haberse caído, pero me callo y lo pienso en silencio.

Escucho una voz muy extraña, alguien me llama, pero no me doy cuenta quién es. Es una llama color caramelo que me dice: Cierra la ventana niño, veo la sierra y me pongo nostálgica.

De pronto, estoy en el campo con muchos caballos y debo herrar herraduras, son muchas y tengo miedo de errar. Cuando termino mi tarea, le digo a mi caballo preferido: Vaya pingo vaya, corra tras las vallas porque él también estaba cansado y necesitaba distraerse.

Vuelvo a mi casa, quiero entrar, pero la puerta no abría, me pregunto: ¿No habría que buscar otra llave?

Como este sueño es muy extraño, voy a tomar nota de él. Me sentaré en un banco y mientras 
canto una linda canción, haré una lista de todos los personajes que han intervenido. Va a ser extraño hacer un cuento con este sueño, pero se lo mostraré a mi maestra y seguramente ella podrá enseñarme lo que de él debo aprender.

(CASTELLO, 2012).

2. Lee el texto otra vez e intenta comprender los homónimos que has subrayado. No te olvides de registrar tus comprensiones.

3. Escribe los homónimos que no hayas comprendido en la columna de la izquierda del cuadro abajo. En seguida, busca en un diccionario monolingüe su(s) significado(s) y escríbelo(s) en la columna de la derecha.

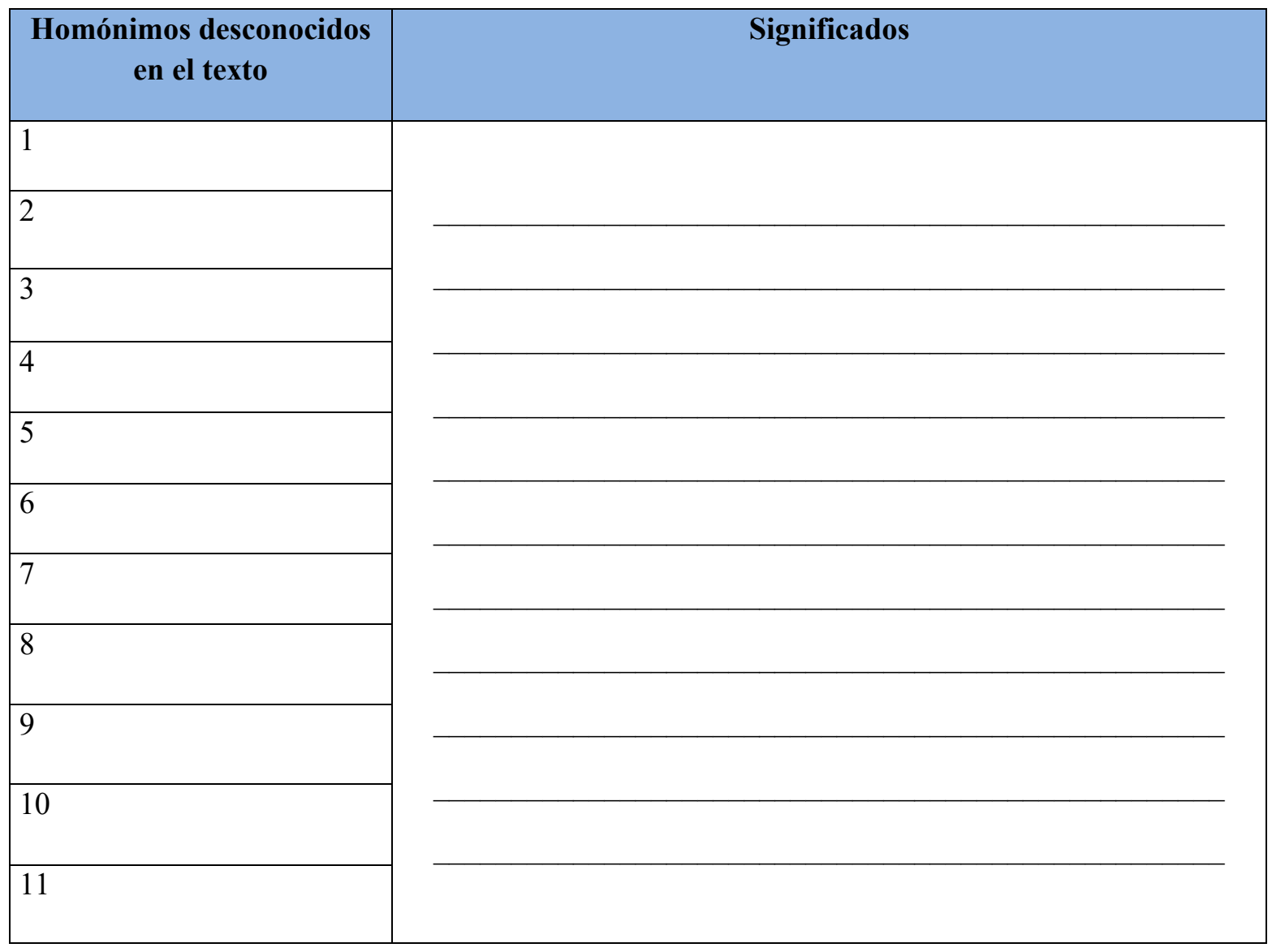

4. Ahora, como ya conoces los significados de las palabras, escribe un texto en que utilices, por lo menos, la mitad de las palabras homónimas escritas y definidas en el ejercicio anterior.

5. Por fin, en parejas, discutan sobre los dos textos, "Un sueño extraño" y el que escribiste en el ejercicio anterior. En la secuencia, tendrás dos opciones para hacer con los otros compañeros de clase: i) hacer un resumen hablado del texto leído y; ii) hablar respecto al texto producido en el ejercicio 4, explicando las diferencias y las semejanzas en relación al asunto tratado en esta actividad. 
Con los ejercicios presentados, ponemos énfasis en la importancia del trabajo con el léxico, para que haya una mirada más cuidadosa con las unidades léxicas homónimas y para que el diccionario sea utilizado con el valor que nos cabe dedicarle en nuestras estrategias de enseñanza y de aprendizaje dentro y fuera de la sala de clase.

\section{Conclusiones}

Terminamos nuestro texto poniendo de relieve el valor del léxico en la lengua, puesto que él siempre ha cumplido un importante papel en la sociedad. Con el léxico se nombra, se orienta en el espacio, se establece o se deshace relaciones, se expresa sentimientos e intenciones comunicativas diversas, en el seno de la multitud de significados posibles. Con el léxico, se puede ir lejos, así como se puede quedar en el lugar donde no haya sabido qué usar para decir lo que se quiera. El léxico es así, poseedor de un poder incalculable en las manos de la sociedad.

Con este artículo, tuvimos el objetivo de poner de relieve la importancia del diccionario en el proceso de enseñanza de E/LE, más específicamente del léxico homónimo del español como perteneciente del léxico general y, por ello, también tan importante en el proceso de enseñanza y de aprendizaje de lenguas.

A partir de las reflexiones y de las propuestas de ejercicios, en que proponemos actividades dirigidas, esperamos haber suscitado la posibilidad de una mirada más cuidadosa a esta parte del léxico en la enseñanza de lenguas, en especial al español, idioma que me ha servido de comunicación en distintos contextos de su enseñanza, de investigaciones sobre el léxico, sobre Lexicografía, sobre Lexicología y sobre diferentes manifestaciones lingüísticas.

\section{Referencias}

ANTUNES, Irandé. Muito além da gramática: por um ensino de línguas sem pedras no caminho. São Paulo: Parábola Editorial, 2007.

ALVAR EZQUERRA, Manuel. La enseñanza del léxico y el uso del diccionario. Madrid: Arco Libros, S.L., 2003.

ALMEIDA FILHO, José Carlos Paes. Dimensões comunicativas no ensino de línguas. $7^{\mathrm{a}}$ Edição. Campinas, SP: Pontes Editora, 2013.

BIDERMAN, Maria Teresa Camargo. Polissemia versus homonímia. In.: Anais do Seminário do GEL XXXVIII, Franca: Unifran - União das Faculdades Franciscanas, 1991. 
. Unidades complexas do léxico. In: RIO-TORTO, G. et al. (org.) Estudos em homenagem ao Professor Doutor Mário Vilela.1a ed. Porto (Portugal): Faculdade de Letras da Universidade do Porto, 2005. p. 747-757.

CANALE, M.; SWAIN, M. Theoretical Bases os Communicative Approaches to Second Language Teaching and Testing. In.: Applied Linguistics, vol. , n. 2, 1980.

CASTELLO, Liana. Un sueño extraño. In: Encuentos: cuentos infantiles para niños. 2012. Disponible en: http://www.encuentos.com/recursos-educativos/un-sueno-extrano-uso-dehomonimos-y-paronimos/. Acceso en: 20 de agosto de 2014.

CASTILLO CARBALLO; M. A.; GARCÍA PLATERO, J. M. La lexicografía didáctica. In: Medina Guerra, A. M. (coord.). Lexicografía Española. Barcelona: Ariel, 2003, pp. 333-351.

CHOMSKY, N. Aspects of the Theory of Syntax. Cambridge, Mass.: The MIT Press, 1965.

DICCIONARIO DE TÉRMINOS CLAVE DE E/LE. In.: Centro Virtual Cervantes. Disponible en: https://cvc.cervantes.es/ensenanza/biblioteca_ele/diccio_ele/default.htm. Acceso el: 29 de septiembre de 2018.

ERES FERNÁNDEZ, Gretel. Entre enfoques y métodos: algunas relaciones (in)coherentes en la enseñanza de español lengua extranjera. In.: BARROS, Cristiano Silva de; COSTA, Elzimar Goettenauer de Marins. Espanhol: ensino médio. Brasília: Ministério da Educação, Secretaria de Educação Básica, 2010.

GARCIA, O. M. Comunicação em prosa moderna. Rio de Janeiro: Editora da fundação Getúlio Vargas, 1977.

GONZÁLEZ, M. C. Diccionario de español para extranjeros - Con el español que se habla hoy en España y en América Latina. Coordinación y proyecto editorial Concepción. São Paulo: edições SM, 2005.

GUTIÉRREZ CUADRADO, Juan; PASCUAL RODRÍGUES, José Antonio. Diccionario salamanca - español para extranjeros. Santillana Educación: Madrid, 2006.

HERNÁNDEZ, H. El nacimiento de la lexicografía monolingüe española para usuarios extranjeros. In: M. RUEDA; E. PRADO, J. LE MEN; F. J. GRANDE (org.). Actuales tendencias en la enseñanza del español como lengua extranjera II. Universidad, León, 1996, p. 203-2010.

La lexicografía didáctica del español: aspectos históricos y críticos. In: FUENTES MORÁN, M. T. (Org.) Lexicografías iberorrománicas: problemas, propuestas proyectos. Madrid: Iberorrománica, 1998, p. 49-79.

. El diccionario en la enseñanza de E. L. E. (Diccionarios de español para extranjeros). In. ASELE. Actas XI (2000).

HIGUERAS, M. Favorecer el aprendizaje del léxico. In: Boletín de la Asociación para la Enseñanza del Español como Lengua Extranjera, 23, 2000, p. 13-18. 
HIMES, D. On Communicative Competence (extracts). In.: BRUMFIT, C. J.; JOHNSON (Orgs.). The Communicative Approach to Language Teaching. Oxford: Oxford University Press, 1979.

KRIEGER, M. da G. In: XATARA, C.; BeVilaCQUA, C. R.; HUMBLÉ, P. R. (orgs). Dicionários na teoria e na prática: como e para quem são feitos. São Paulo: Parábola Editorial, 2011.

. O dicionário de língua como potencial instrumento didático. In: ISQUERDO, A. N.; ALVES, I. M. (ORG.). As ciências do léxico: lexicologia, lexicografia e terminologia, volume III. São Paulo: Humanitas, 2007.

MARTÍNEZ MARÍN, Juan. El diccionario y la enseñanza-aprendizaje del español como lengua extranjera. In: Actas del Primer Congreso Nacional de ASELE, Granada, Universidad de Granada, 1990, p. 307-315.

MARTÍN GARCÍA, Joseja. El diccionario en la enseñanza del español. Madrid: Arco Libros, S. L. 1999.

MCER. Marco Común Europeo de Referencia para las lenguas: aprendizaje, enseñanza, evaluación. Madrid, Secretaria General Técnica del MCER y Grupo Anaya, Traducido y adaptado por el Instituto Cervantes, 2002.

MORANTE VALLEJO, Roser. El desarrollo del conocimiento léxico em segundas lenguas. Madrid: Arco Libros, S.L., 2005.

NADIN, O. L. O uso do dicionário nas aulas de español como língua estrangeira: reflexões teórico-práticas. In: NADIN, O. L,; LUGLI, V. C. P. (Org.). Espanhol como língua estrangeira. 1. Ed. Campinas, SP: Mercado das Letras, 2013.

PRADO ARAGONÉS, Josefina. El ejemplo lexicográfico como referente cultural en la enseñanza del español como lengua extranjera. In. ARAGONÉS, Josefina Prado; CAMACHO, Maria victoria Galloso. Diccionario, Léxico y cultura. Huelva: Universidad de Huelva, 2004.

PEREIRA, Renato Rodrigues. O diccionario pedagógico e a homonímia: em busca de parâmetros didáticos. Tese (Doutorado em Linguística e Língua Portuguesa). Universidade Estadual Paulista "Júlio de Mesquita Filho", Araquara, 2018, p. 209.

SÁNCHEZ, Aquilino. Diccionario abreviado de uso del español actual. Sociedad General Española de Librería, S. A. Alcobendas-Madrid, 2003.

SÁNCHEZ LÓPEZ, Isabel. Léxico, diccionario y enseñanza/aprendizaje de ELE. ASELE.Colección Monografías (Tesis de Doctorado), 2013.

TARONE, E. Communication Strategies, Foreign Talk and Repair in Interlanguage. Language learning, vol. 30/2, 1980.

ULLMANN, Stephen. Semântica: uma introdução à ciência do significado. Tradução de J.A. Osório Mateus. Lisboa: Fundação Calouste Gulbenkian, 1964. 
WELKER, Herbert Andreas. Lexicografia Pedagógica: definições, história, peculiaridades. In: XATARA, C.; BEVILACQUA, C.; HUMBLÉ, P.. Lexicografia Pedagógica: pesquisas e perspectivas. Santa Catarina: NUT, 2008.

WIDDOWSON, H. G. Knowledge of Language and Ability for Use. In.: Applied Linguistics, vol. 10/2, 1989.

ZAVAGLIA, Claudia. Ambiguidade gerada pela homonímia: revisitação teórica, linhas limítrofes com a polissemia e proposta de critérios distintivos. DELTA: Documentação de Estudos em Linguística Teórica e Aplicada, São Paulo, v. 1, n. 19, p. 337 - 366, 2003.

; MURAKAWA, Clotilde de Almeida Azevedo. Questões teóricas específicas. In.: XATARA, Claudia; BEVILACQUA, Cleci Regina; HUBLÉ, Philipe René Marie. Dicionários na teoria e na prática: como e para quem são feitos. São Paulo: Parábola, 2011. 